\title{
Posterior odontoid process angulation in pediatric Chiari I malformation: an MRI morphometric external validation study
}

\author{
Travis R. Ladner, BA, ${ }^{1}$ Michael C. Dewan, MD, ${ }^{1}$ Matthew A. Day, MD, ${ }^{2}$ \\ Chevis N. Shannon, MBA, MPH, DrPH, ${ }^{1}$ Luke Tomycz, MD, ${ }^{3}$ Noel Tulipan, MD, ${ }^{1}$ and \\ John C. Wellons III, MD, MSPH ${ }^{1}$
} ${ }^{1}$ Department of ${ }^{1}$ Neurological Surgery and ${ }^{2}$ Radiology, Vanderbilt University School of Medicine, Nashville, Tennessee; and
3Department of Neurological Surgery, Dell Children's Medical Center of Central Texas, Austin, Texas

\begin{abstract}
OBJECT Osseous anomalies of the craniocervical junction are hypothesized to precipitate the hindbrain herniation observed in Chiari I malformation (CM-I). Previous work by Tubbs et al. showed that posterior angulation of the odontoid process is more prevalent in children with $\mathrm{CM}$-I than in healthy controls. The present study is an external validation of that report. The goals of our study were 3-fold: 1) to externally validate the results of Tubbs et al. in a different patient population; 2) to compare how morphometric parameters vary with age, sex, and symptomatology; and 3) to develop a correlative model for tonsillar ectopia in CM-I based on these measurements.
\end{abstract}

METHODS The authors performed a retrospective review of 119 patients who underwent posterior fossa decompression with duraplasty at the Monroe Carell Jr. Children's Hospital at Vanderbilt University; 78 of these patients had imaging available for review. Demographic and clinical variables were collected. A neuroradiologist retrospectively evaluated preoperative MRI examinations in these 78 patients and recorded the following measurements: McRae line length; obex displacement length; odontoid process parameters (height, angle of retroflexion, and angle of retroversion); perpendicular distance to the basion-C2 line (pB-C2 line); length of cerebellar tonsillar ectopia; caudal extent of the cerebellar tonsils; and presence, location, and size of syringomyelia. Odontoid retroflexion grade was classified as Grade 0, > $90^{\circ}$; Grade I, $85^{\circ}-89^{\circ}$; Grade II, $80^{\circ}-84^{\circ}$; and Grade III, <80 . Age groups were defined as $0-6$ years, 7-12 years, and 13-17 years at the time of surgery. Univariate and multivariate linear regression analyses, Kruskal-Wallis 1-way ANOVA, and Fisher's exact test were performed to assess the relationship between age, sex, and symptomatology with these craniometric variables.

RESULTS The prevalence of posterior odontoid angulation was $81 \%$, which is almost identical to that in the previous report $(84 \%)$. With increasing age, the odontoid height $(p<0.001)$ and $p B-C 2$ length $(p<0.001)$ increased, while the odontoid process became more posteriorly inclined $(p=0.010)$. The $p B-C 2$ line was significantly longer in girls $(p=$ $0.006)$. These measurements did not significantly correlate with symptomatology. Length of tonsillar ectopia in pediatric CM-I correlated with an enlarged foramen magnum $(p=0.023)$, increasing obex displacement $(p=0.020)$, and increasing odontoid retroflexion $(p<0.001)$.

CONCLUSIONS Anomalous bony development of the craniocervical junction is a consistent feature of CM-I in children. The authors found that the population at their center was characterized by posterior angulation of the odontoid process in $81 \%$ of cases, similar to findings by Tubbs et al. (84\%). The odontoid process appeared to lengthen and become more posteriorly inclined with age. Increased tonsillar ectopia was associated with more posterior odontoid angulation, a widened foramen magnum, and an inferiorly displaced obex.

http://thejns.org/doi/abs/10.3171/2015.1.PEDS14475

KEY WORDS Chiari I malformation; syringomyelia; craniocervical junction; morphometry; dens

ABBREVIATIONS CCJ = craniocervical junction; $\mathrm{CM}-\mathrm{I}=$ Chiari I malformation .

SUBMITTED September 10, 2014. ACCEPTED January 22, 2015.

INCLUDE WHEN CITING Published online May 22, 2015; DOI: 10.3171/2015.1.PEDS14475.

DISCLOSURE The authors report no conflict of interest concerning the materials or methods used in this study or the findings specified in this paper. T.R.L. received funding from the CNS/CSNS Medical Student Summer Fellowship in Socioeconomic Research. 


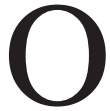
SSEOUS anomalies of the craniocervical junction (CCJ) are hypothesized to precipitate the hindbrain herniation observed in Chiari I malformation (CM-I). One previous single-center study by Tubbs et al. showed that posterior angulation of the odontoid process is more prevalent in children with CM-I than in healthy controls. ${ }^{20}$ The present study is an external validation of that report. The goals of our study are 3 -fold: 1 ) to externally validate the results of Tubbs et al. in a different patient population; 2) to compare how morphometric parameters vary with age, sex, and symptomatology; and 3 ) to develop a correlative model for tonsillar ectopia in CM-I based on these measurements. It is our hope that this effort will yield greater insight into the structural features and pathogenesis of CM-I in children.

\section{Methods \\ Patient Assessment}

After obtaining institutional board review approval, a database of all patients younger than 18 years who underwent posterior fossa decompression at the Monroe Carrell Jr. Children's Hospital at Vanderbilt University, Nashville, Tennessee, between January 1998 and August 2012 was retrospectively created from medical records and review of images. A total of $78 \mathrm{CM}$-I patients with preoperative MRI studies were identified. Clinical, demographic, and radiological data were retrieved from these patients' records.

\section{Radiological Data}

A single neuroradiologist (M.A.D.) retrospectively evaluated preoperative MRI examinations in 78 patients for whom imaging was available, as has been described previously. ${ }^{11}$ Markup tools included in IMPAX (AGFA Healthcare) were used for all measurements. The radiological measurement methodology has been previously described by Tubbs et al. ${ }^{20} \mathrm{~A}$ diagram of each of the measurements used in this study is presented in Fig. 1. The preoperative midsagittal T1-weighted MRI sequence of the brain was used for the following measurements (note that in a minority of cases $[n=20]$ without a preoperative brain MRI study available, the midsagittal T2-weighted MRI sequence of the cervical spine was used to obtain the same measurements): McRae line, vertical distance of the obex to the midpoint of McRae line, vertical distance of the tonsils below the McRae line, distance of tonsils below the midpoint of the McRae line (defined here as tonsillar ectopia), basiocciput length, clivus length, and caudal extent of the tonsils in relation to the $\mathrm{C} 1-2$ posterior arches. In preparation for this study, we found that the basiocciput measure was often inconsistent due to technical artifacts and/or a fused/distorted spheno-occipital synchondrosis. While we retained the basiocciput measurement to maintain consistency in the literature, the clivus length, which was not originally measured in the Tubbs et al. study, was selected as an additional, more consistent, and reproducible proxy measure for posterior fossa size. Basiocciput measurement was possible in 67 cases $(85.9 \%)$, and measurement of the clivus length was possible in 68 cases (87.2\%).

The preoperative midsagittal T2-weighted MRI sequence of the cervical spine was used for the follow-
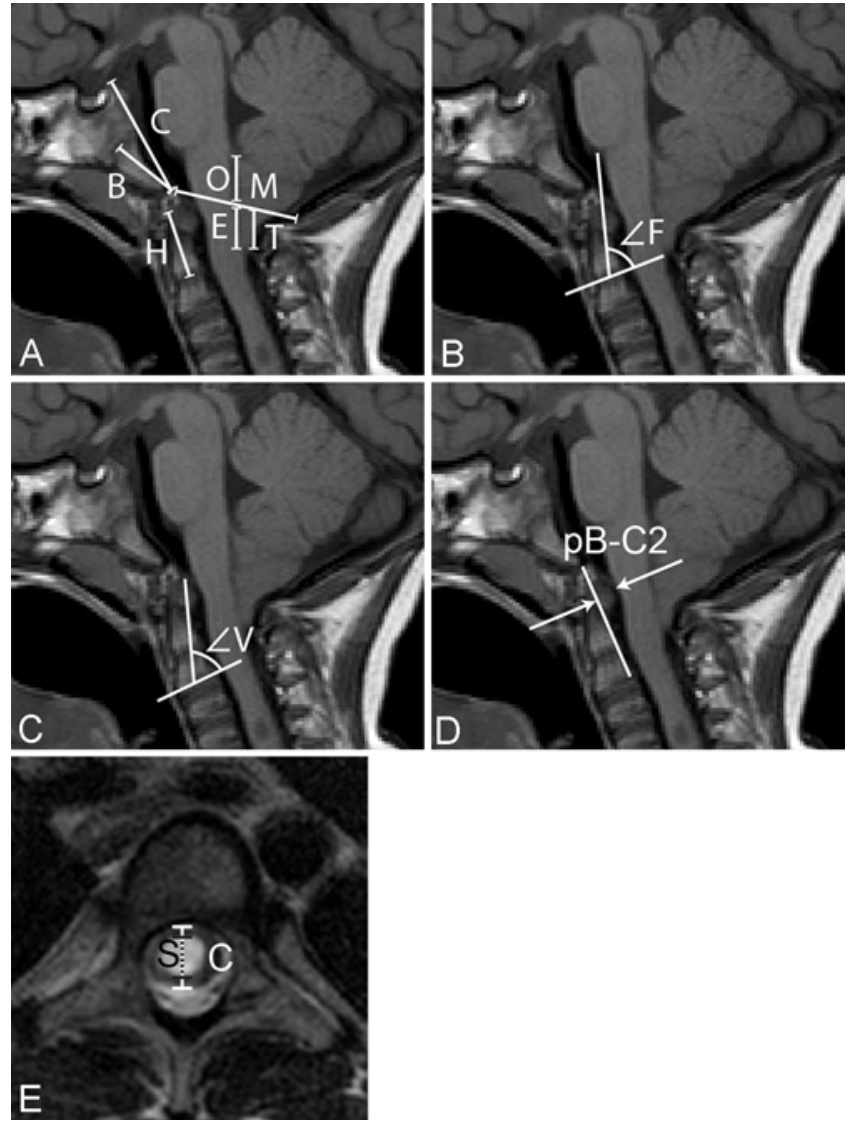

FIG. 1. Measurements made on MR images. A: $B=$ basiocciput, measured from basion to sphenooccipital synchrondosis; $C$ = clivus length, measured from basion to the posterior clinoid process; $E=$ distance from caudal extent of tonsils to the midpoint of McRae line; $\mathrm{H}=$ odontoid process height; $\mathrm{M}=\mathrm{McRae}$ line; $\mathrm{O}=$ distance from obex to midpoint of McRae line; T = vertical distance of tonsils below McRae line. B: Angle $F$ is the angle of retroflexion, formed between a line drawn through the odontoid synchondrosis and its intersection with a line drawn from the odontoid tip. C: Angle $\mathrm{V}$ is the angle of retroversion, formed between the line drawn from the base of $\mathrm{C}-2$ and its intersection with a line drawn from the odontoid tip. $\mathrm{D}$ : The $\mathrm{pB}-\mathrm{C} 2$ line (between the arrows) is drawn perpendicular to the line from the $\mathrm{C}-2$ body and the basion, at the posterior extent of the odontoid process. E: $\mathrm{C}=$ cord diameter at the level of the maximum syrinx diameter; $S=$ maximum syrinx diameter is drawn through the longest anteroposterior segment in the axial plane. Note: Panels B-D demonstrate T1-weighted imaging for illustrative purposes; however, in the study these measurements were made using T2-weighted imaging (such as in Fig. 2). Reproduced with permission from Ladner et al: J Neurosurg Pediatr 15:178-188, 2015.

ing length measurements: odontoid length, $\mathrm{pB}-\mathrm{C} 2$ line (drawn perpendicular to a line drawn between the basion and the posterior aspect of the C-2 vertebral body, at the most posterior extent of the odontoid process at the dural interface), angle of odontoid process retroflexion, and angle of retroversion. The following measurements/observations were made of the preoperative spine MR images using the T2-weighted axial and sagittal sequences. The presence or absence of a syrinx was assessed. If present, the region of cord involvement (cervical, thoracic, or lumbar), cord region with maximal syrinx diameter, maximal syrinx diameter, and diameter of the cord at the level of maximal syrinx diameter were recorded. The maximal 
axial anteroposterior extent was used for syrinx and cord diameter measurements.

\section{Data Analysis}

Patients were stratified by odontoid retroflexion grade, age, sex, and symptomatology and were separately analyzed. Odontoid angulation grade was classified as previously defined by Tubbs et al.: Grade $0,>90^{\circ}$; Grade I, $85^{\circ}-89^{\circ}$; Grade II, $80^{\circ}-84^{\circ}$; and Grade III, $<80^{\circ} .{ }^{20}$ Age groups were defined as $0-6$ years, 7-12 years, and 13-17 years at the time of operation. With regard to symptomatology, asymptomatic patients were defined as those having no symptoms referable to CM-I (i.e., no headaches, back/ neck pain, cranial nerve palsies, central apnea, dysesthesias, sensory loss, or motor weakness reported and/or present on physical examination), and symptomatic patients were defined as those having any of these constellations of symptoms. As this was a surgical series, asymptomatic patients generally presented with syrinx found incidentally during imaging for another reason (e.g., scoliosis workup or trauma) or profound tonsillar ectopia found during unrelated head imaging for seizures, hydrocephalus, concussion, or other head trauma.

\section{Statistical Analysis}

All statistical analyses were performed using SPSS Statistics (version 21, IBM). The Shapiro-Wilk test for normality of measurements found a nonnormal distribution; therefore, nonparametric tests were used. For continuous variables, statistical analysis was performed using Kruskal-Wallis 1-way ANOVA with post hoc Tukey's honest significance test for groups of 3 or more and the MannWhitney U-test for groups of 2. For categorical variables, the Fisher's exact test was used. Relevant measurements, syrinx presence, and tonsil positions were compared across 1) the 4 odontoid angulation grades (Grades $0-$ III); 2) the 3 age groups (0-6, 7-12, and 13-17 years); 3 ) male and female sexes; and 4) symptomatic versus asymptomatic. Univariate linear regression modeling was performed in 3 separate analyses: odontoid retroflexion (independent, continuous) versus the various CCJ measurements (dependent, continuous); age (independent, continuous) versus various CCJ measurements (dependent, continuous); and various CCJ measurements (independent, continuous variables only) versus tonsillar ectopia (dependent, continuous). For the analysis of tonsillar ectopia, multivariate analysis was constructed from variables with $\mathrm{p}<0.20$ on univariate analysis using stepwise backward linear regression, with case correction removing outliers greater than 3 standard deviations from the mean. All statistical analyses performed assumed $p<0.05$ for significance and $p<0.10$ for identification of trends. Given the nonnormal distribution of our cohort, comparisons of the Vanderbilt University cohort to the cohort from the Children's Hospital of Alabama at the University of Alabama-Birmingham (Tubbs et al.) are made qualitatively. ${ }^{20}$

\section{Results}

\section{Patient Characteristics}

The mean age of the patients was 8.1 (SD 4.1) years; $55.1 \%$ of patients were female. The racial/ethnic distribu- tion was as follows: 91\% White/non-Hispanic, 5.1\% White/ Hispanic, and 3.8\% Black/African descent. The most frequent spinal anomalies included scoliosis (20.5\%) and atlantooccipital fusion (1.3\%). Other common diagnoses included hydrocephalus (3.8\%), epilepsy (1.3\%), and neurofibromatosis Type 1 (2.5\%). Metabolic abnormalities were rare: idiopathic growth hormone deficiency $(1.3 \%)$ and vitamin D-resistant rickets (1.3\%). There was a family history of CM-I in $1.3 \%$ of patients. All patients subsequently underwent posterior fossa decompression with duraplasty.

\section{External Validation of CCJ Measurements}

The mean age of CM-I patients at Vanderbilt (8.1 years) was similar to that of the Tubbs et al. CM-I cohort (9 years). ${ }^{20}$ The mean CCJ measurements for all CM-I patients are listed in Table 1 . The prevalence of a posteriorly inclined odontoid process (i.e., Grade I or greater) in our cohort $(81 \%)$ was nearly identical to that in the Tubbs et al. CM-I cohort (84\%) (Fig. 2). For reference, within the Tubbs et al. controls, only $10 \%$ of patients had posterior odontoid angulation. The mean degree of retroflexion was smaller in our cohort: $81.4^{\circ}$ versus $98^{\circ}$; however, retroversion was comparable: $72.2^{\circ}$ versus $70^{\circ}$.

The most striking difference between cohorts was the longer distance from the obex to the McRae line in our population (13.9 vs $2.1 \mathrm{~mm})$. This measurement is much closer to that in the control group in the Tubbs et al. study $(10 \mathrm{~mm})$. There was a greater proportion of patients with a syrinx in our cohort as well: $69.2 \%$ versus $52 \%$. The other measurements were similar to those in Tubbs et al. In particular, basiocciput length $(22 \mathrm{~mm})$ was comparable to that in the Tubbs et al. study, which found no difference in length between patients $(23 \mathrm{~mm})$ and controls $(23 \mathrm{~mm})$.

\section{CCJ Measurements Stratified by Odontoid Retroflexion Grade}

Table 1 demonstrates the various CCJ measurements stratified by the grade of odontoid retroflexion. Both tonsillar ectopia (Kruskal-Wallis: $\mathrm{p}=0.015$; univariate regression: $\mathrm{p}=0.001, \mathrm{R}^{2}=0.133$ ) and $\mathrm{pB}-\mathrm{C} 2$ length (Kruskal-Wallis: $p=0.021$; univariate regression: $p<0.001, R^{2}$ $=0.152$ ) increased with increasing angulation grade. However, the vertebral level of the caudal tonsil position did not correlate significantly with angulation grade; neither did presence of syrinx correlate with angulation grade, which is contrary to the findings by Tubbs et al. ${ }^{20}$

\section{CCJ Measurements Stratified by Age Group}

Table 2 demonstrates the various measurements stratified by age. The odontoid process was longer (KruskalWallis: $\mathrm{p}<0.001$; univariate regression: $\mathrm{p}<0.001, \mathrm{R}^{2}=$ 0.407 ) and more retroverted (Kruskal-Wallis: $p=0.008$; univariate regression: $\mathrm{p}<0.001, \mathrm{R}^{2}=0.158$ ) as patient age increased. The odontoid process also extended into the ventral canal to a greater extent (i.e., the $\mathrm{pB}-\mathrm{C} 2$ line lengthens) with increasing patient age (Kruskal-Wallis: $\mathrm{p}$ $<0.001$; univariate regression: $\left.\mathrm{p}<0.001, \mathrm{R}^{2}=0.196\right)$. The 7- to 12-year-old group was more likely to have a syrinx ( $\mathrm{p}$ $=0.029)$, particularly a cervical syrinx $(\mathrm{p}=0.014)$, compared with the 0 - to 6-year-old group. 
TABLE 1. Morphometric data by odontoid angulation grade*

\begin{tabular}{|c|c|c|c|c|c|c|}
\hline Measurement & All $(n=78)$ & Grade $0(n=15)$ & Grade I $(n=13)$ & Grade II $(n=13)$ & Grade III $(n=37)$ & $\mathrm{p}$ Value \\
\hline Mean McRae line & $34.3(4.1)$ & $35.5(4.1)$ & $33.4(3.3)$ & $34.2(4.4)$ & $34.2(4.1)$ & 0.534 \\
\hline Mean obex displacement & $13.9(3.9)$ & $14.3(3.3)$ & $13.6(5.5)$ & $13(3.9)$ & $14.1(3.5)$ & 0.871 \\
\hline Mean odontoid height & $16.9(2.9)$ & $16.9(2.9)$ & $16.3(3.6)$ & $16.8(2.4)$ & $17.2(2.8)$ & 0.861 \\
\hline Mean tonsillar ectopia & $14.6(6)$ & $10.7(4.4)_{\mathrm{a}}$ & $13.6(5.8)_{\mathrm{ab}}$ & $17.2(4.8)_{b}$ & $15.6(6.3)_{\mathrm{ab}}$ & 0.015 \\
\hline Mean basiocciput length & $22(3.6)$ & $24.1(3.8)$ & $21(3.4)$ & $21.7(2.9)$ & $21.5(3.6)$ & 0.146 \\
\hline Mean clivus length & $37.8(5.2)$ & $40(6.8)$ & $36.3(5.5)$ & $37.4(3.4)$ & $37.6(4.8)$ & 0.468 \\
\hline Mean retroflexion $\left({ }^{\circ}\right)$ & $81.4(11.1)$ & $98.8(7.7)_{\mathrm{a}}$ & $86.5(1.3)_{b}$ & $81.4(0.9)_{c}$ & $72.5(4.9)_{\mathrm{d}}$ & $<0.001$ \\
\hline Mean retroversion $\left({ }^{\circ}\right)$ & $72.2(5.4)$ & $76.7(4.7)_{\mathrm{a}}$ & $75.2(5.4)_{\mathrm{ab}}$ & $72.5(3.4)_{b c}$ & $69.2(4.4)_{\mathrm{c}}$ & $<0.001$ \\
\hline Mean $\mathrm{pB}-\mathrm{C} 2$ line & $3.5(2)$ & $2.6(1.6)$ & $3(1.7)$ & $3(1.8)$ & $4.3(2.1)$ & 0.021 \\
\hline Mean syrinx size & $7.2(3.5)$ & $5.8(4)$ & $7(3.7)$ & $7.4(2.8)$ & $7.8(3.5)$ & 0.416 \\
\hline Syrinx & $54(69.2 \%)$ & $11(73.3 \%)$ & $8(61.5 \%)$ & $10(76.9 \%)$ & $25(67.6)$ & - \\
\hline Cervical & $44(56.4 \%)$ & $7(46.7 \%)$ & $6(46.2 \%)$ & $8(61.5 \%)$ & $23(62.2)$ & - \\
\hline Thoracic & $45(57.7 \%)$ & $8(53.3 \%)$ & $7(53.8 \%)$ & $8(61.5 \%)$ & 22 (62.2) & - \\
\hline Lumbar & $10(12.8 \%)$ & $2(13.3 \%)$ & $1(7.7 \%)$ & $4(30.8 \%)$ & $3(8.1)$ & - \\
\hline \multicolumn{7}{|l|}{ Tonsil position } \\
\hline Above C-1 & $3(3.8 \%)$ & $0(0 \%)$ & $1(7.7 \%)$ & $0(0 \%)$ & $2(5.4 \%)$ & - \\
\hline C-1 & $39(49.4 \%)$ & $11(73.3 \%)$ & $7(53.8 \%)$ & $5(38.5 \%)$ & $16(43.2 \%) \dagger$ & - \\
\hline C1-2 & $17(21.5 \%)$ & $2(13.3 \%)$ & $2(15.4 \%)$ & $4(30.8 \%)$ & $9(24.3 \%)$ & - \\
\hline $\mathrm{C}-2$ & $20(25.3 \%)$ & $2(13.3 \%)$ & $3(23.1 \%)$ & $4(30.8 \%)$ & $10(27 \%)$ & - \\
\hline
\end{tabular}

$-=p$ was uncalculated across groups.

* All linear measurements are given in mm unless indicated otherwise. Mean data are displayed as the mean (SD). All other non-p values represent the number of patients. Mean values not sharing the same subscript (i.e., a, b, c, and d) vary significantly by $p<0.05$.

$\dagger p<0.10$ compared with Grade 0 .

\section{CCJ Measurements Stratified by Sex}

Table 3 demonstrates the various measurements stratified by sex. In female patients, the odontoid process was slightly more retroverted $(\mathrm{p}=0.046)$, with a longer $\mathrm{pB}-\mathrm{C} 2$ line $(p=0.006)$. Although there was no significant difference in syrinx prevalence or location, syringes in male patients were larger on average $(p=0.036)$. However, this may be related to a larger cord diameter at the level of syrinx (more common in the lumbar spine) in males (11 vs 9.3 $\mathrm{mm}, \mathrm{p}=0.027$ ), with no statistically significant difference in the ratio between syrinx diameter and cord diameter.
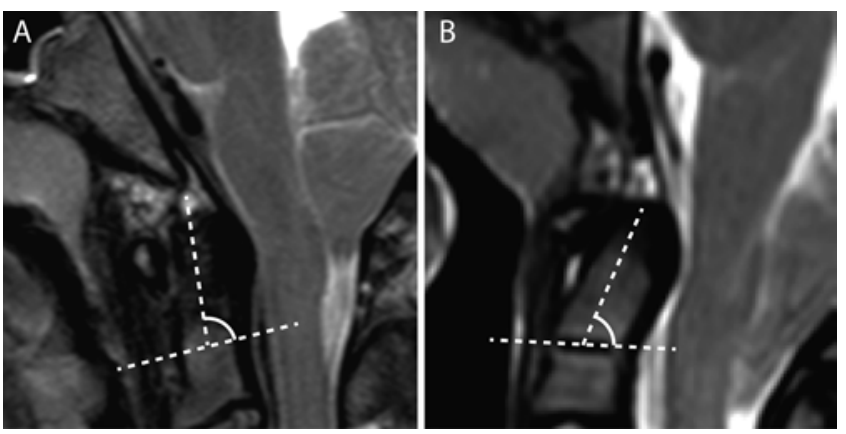

FIG. 2. A: Grade 0 odontoid retroflexion, with $94^{\circ}$ of retroflexion, 11 $\mathrm{mm}$ of tonsillar ectopia. The odontoid synchondrosis has fused in this patient. The arm for angle measurement has been drawn through the synchondrosis scar instead. B: Grade III odontoid retroflexion, with $65^{\circ}$ of retroflexion, $22 \mathrm{~mm}$ of tonsillar ectopia.

\section{CCJ Measurements Stratified by Symptomatology}

In this cohort, 55 patients (70.5\%) were symptomatic. Headaches were the most common symptom, present in $53.9 \%$ of patients. Symptoms of axial or appendicular pain/ dysesthesia were the second most common: neck pain, $11.5 \%$; back pain, $5.2 \%$; upper-extremity pain/numbness, $10.2 \%$; and lower-extremity pain/numbness, $7.7 \%$. Cranial nerve deficits/symptoms of brainstem compression were present in less than 5\% of patients. Notably, there were no differences in radiographic measurements in symptomatic versus asymptomatic patients. However, asymptomatic patients were significantly more likely to present with a syrinx $(p=0.033)$, especially a cervical syrinx $(p=0.003)$.

\section{Modeling MRI Morphometric Correlates of Tonsillar Ectopia}

Univariate and multivariate analyses of measurements versus tonsillar ectopia (dependent) are summarized in Table 4. Variables meeting threshold on univariate analysis (i.e., $p<0.20$ ) were entered into a multivariate analysis. Following stepwise permutations, the following variables were used for the final multivariate linear regression model: McRae line ( $p=0.023)$, obex displacement $(p=0.020)$, and odontoid retroflexion $(\mathrm{p}<0.001)$. These 3 variables significantly correlated with tonsillar ectopia: $\mathrm{F}(3,74)=$ $8.581, \mathrm{p}<0.001, \mathrm{R}^{2}=0.258$. However, there was no relationship between clinical and demographic characteristics and degree of ectopia on univariate analyses. 
TABLE 2. Morphometric data by age*

\begin{tabular}{|c|c|c|c|c|}
\hline Measurement & $0-6$ Yrs $(n=33)$ & $7-12$ Yrs $(n=31)$ & $13-17$ Yrs $(n=14)$ & $p$ Value \\
\hline Mean McRae line & $33.8(3.9)$ & $34(4.3)$ & $36(3.9)$ & 0.193 \\
\hline Mean obex displacement & $13.8(4.1)$ & $14.1(4.4)$ & $14.1(4.4)$ & 0.976 \\
\hline Mean odontoid height & $15.1(2.5)_{a}$ & $19.1(1.9)_{b}$ & $19.1(1.9)_{b}$ & $<0.001$ \\
\hline Mean tonsillar ectopia & $14(5.7)$ & $13.8(6.4)$ & $13.8(6.4)$ & 0.663 \\
\hline Mean basiocciput length & $20.8(2.5)$ & $22.5(3.5)$ & $27.6(5)$ & 0.003 \\
\hline Mean clivus length & $35.6(3.6)$ & $39.1(5)$ & $41.1(7.4)$ & 0.003 \\
\hline Mean retroflexion $\left({ }^{\circ}\right)$ & $84.7(10.7)$ & $80(10.5)$ & $76.6(11.7)$ & 0.045 \\
\hline Mean retroversion $\left({ }^{\circ}\right)$ & $74.4(5.6)_{\mathrm{a}}$ & $71.1(4.9)_{\mathrm{ab}}$ & $69.5(4.5)_{b}$ & 0.008 \\
\hline Mean $\mathrm{pB}-\mathrm{C} 2$ line & $2.2(1.3)_{a}$ & $4.4(1.8)_{b}$ & $4.6(2.1)_{b}$ & $<0.001$ \\
\hline Mean syrinx size & $7.2(4)_{a b}$ & $6.3(3.2)_{a}$ & $9.8(2.2)_{b}$ & 0.038 \\
\hline Syrinx & $19(57.6 \%)$ & $26(83.9 \%) \dagger$ & $9(64.3 \%)$ & - \\
\hline Cervical & $13(39.4 \%)$ & $22(71 \%) \dagger$ & $9(64.3 \%)$ & - \\
\hline Thoracic & $16(48.5 \%)$ & $3(9.7 \%) \ddagger$ & $7(50 \%)$ & - \\
\hline Lumbar & $4(12.1 \%)$ & $9(29 \%)$ & $1(7.1 \%)$ & - \\
\hline \multicolumn{5}{|l|}{ Tonsil position } \\
\hline Above C-1 & $0(0 \%)$ & $0(0 \%)$ & $3(21.4 \%) \dagger$ & - \\
\hline$C-1$ & $15(45.5 \%)$ & $17(54.8 \%)$ & $7(50 \%)$ & - \\
\hline $\mathrm{C} 1-2$ & $8(24.2 \%)$ & $6(19.4 \%)$ & $3(21.4 \%)$ & - \\
\hline $\mathrm{C}-2$ & $10(30.3 \%)$ & $8(25.8 \%)$ & $4(7.1 \%)$ & - \\
\hline \multicolumn{5}{|c|}{$\begin{array}{l}\text { - }=p \text { was uncalculated across groups. } \\
\text { All linear measurements are given in mm unless indicated otherwise. Mean data are displayed as the mean (SD). All other non-p values } \\
\text { represent the number of patients. Means not sharing the same subscript (i.e., a and b) vary significantly by } p<0.05 \text {. } \\
+p<0.05 \text { compared with the } 0-6 \text {-year age group. } \\
\ddagger p<0.10 \text { compared with the } 0-6 \text {-year age group. }\end{array}$} \\
\hline
\end{tabular}

\section{Discussion}

\section{Odontoid Angulation in CM-I and Syringomyelia}

In this study we confirmed the prevalence of posterior angulation of the odontoid process into the ventral canal in CM-I (81\%); $47.4 \%$ of our cases had angulation less than $80^{\circ}$ (Grade III). This is consistent with the figures reported previously by Tubbs et al.: $84 \%$ with angulation and 32\% with Grade III angulation. The findings in our cohort suggest an even more exaggerated posterior odontoid angulation than previously reported, with a more retroflexed mean odontoid angle $\left(81.4^{\circ}\right)$ and a greater percentage with the highest retroflexion grade. In contrast to CM-I patients, Tubbs et al. found that only $10 \%$ of controls demonstrated such posterior angulation. ${ }^{20}$ This may be significant for surgical outcomes, as patients with greater ventral canal encroachment ( $\mathrm{pB}-\mathrm{C} 2$ line $>9 \mathrm{~mm}$ ) may be more likely to require subsequent anterior decompression $^{8}$ and/or fusion; ${ }^{2}$ however, we did not observe this in our series. ${ }^{11}$

In a recent qualitative study, Moore and Moore reported subjective odontoid retroflexion of $80 \%$ in complicated cases and $44 \%$ in uncomplicated pediatric CM-I cases. ${ }^{13}$ While a previous large MRI series by Milhorat et al. reported a prevalence of retroflexion of $26.4 \%$, the radiographic methodology and criteria were different. ${ }^{12}$ Because the measurements used in this study do not require normal axial body morphology to be reliable, we have found that this study confirms that the methodology used by Tubbs et al. is a valid and reproducible means of studying odontoid retroflexion in children with CM-I.
TABLE 3. Morphometric data by sex*

\begin{tabular}{lccr}
\hline \multicolumn{1}{c}{ Measurement } & $\begin{array}{c}\text { Female } \\
(\mathrm{n}=43)\end{array}$ & $\begin{array}{c}\text { Male } \\
(\mathrm{n}=35)\end{array}$ & $\mathrm{p}$ Value \\
\hline Mean McRae line & $33.5(4.3)$ & $35.1(3.8)$ & 0.080 \\
\hline Mean obex displacement & $13.7(3.9)$ & $14.2(3.9)$ & 0.603 \\
\hline Mean odontoid height & $17.2(2.9)$ & $16.6(2.8)$ & 0.363 \\
\hline Mean tonsillar ectopia & $15.3(6)$ & $13.7(6)$ & 0.322 \\
\hline Mean basiocciput length & $21.9(4)$ & $22.1(3.2)$ & 0.761 \\
\hline Mean clivus length & $37.8(5.3)$ & $37.8(5.2)$ & 0.816 \\
\hline Mean retroflexion $\left(^{\circ}\right)$ & $80.6(10.1)$ & $82.3(12.3)$ & 0.550 \\
\hline Mean retroversion $\left({ }^{\circ}\right)$ & $71(5.2)$ & $73.7(5.4)$ & 0.046 \\
\hline Mean pB-C2 line & $4.1(2.1)$ & $2.8(1.7)$ & 0.006 \\
\hline Mean syrinx size & $6.3(3.2)$ & $8.3(3.6)$ & 0.036 \\
\hline Syrinx & $29(67.4 \%)$ & $25(71.4 \%)$ & 0.807 \\
\hline Cervical & $25(58.1 \%)$ & $19(54.3 \%)$ & 0.820 \\
\hline Thoracic & $28(65.1 \%)$ & $17(48.6 \%)$ & 0.171 \\
\hline Lumbar & $3(7 \%)$ & $5(14.3 \%)$ & 0.456 \\
\hline Tonsil position & & & \\
\hline \multicolumn{1}{c}{ Above C-1 } & $1(2.3 \%)$ & $2(5.7 \%)$ & 0.585 \\
\hline C-1 & $19(44.2 \%)$ & $20(57.1 \%)$ & 0.363 \\
\hline C1-2 & $9(20.9 \%)$ & $8(22.9 \%)$ & $>0.999$ \\
\hline C-2 & $14(32.6 \%)$ & $5(14.3 \%)$ & 0.070 \\
\hline
\end{tabular}

* All linear measurements are given in mm unless indicated otherwise. Mean data are displayed as the mean (SD). All other non- $p$ values represent the number of patients. 
TABLE 4. Univariate and multivariate correlates of tonsillar ectopia

\begin{tabular}{|c|c|c|c|c|c|}
\hline \multirow[b]{2}{*}{ Variable } & \multicolumn{3}{|c|}{ Univariate } & \multicolumn{2}{|c|}{ Multivariate* } \\
\hline & B & $\mathrm{R}^{2}$ & $p$ Value & Beta & $p$ Value \\
\hline Age & 0.073 & 0.002 & 0.666 & - & - \\
\hline Sex & -1.565 & 0.017 & 0.254 & - & - \\
\hline McRae line & 0.342 & 0.055 & 0.039 & 0.234 & 0.023 \\
\hline Obex displacement & -0.424 & 0.075 & 0.015 & -0.240 & 0.020 \\
\hline Odontoid height & 0.336 & 0.013 & 0.159 & - & - \\
\hline Basiocciput & -0.081 & 0.002 & 0.669 & - & - \\
\hline Clivus length & 0.006 & 0.000 & 0.969 & - & - \\
\hline Odontoid retroflexion & -0.197 & 0.133 & 0.001 & -0.377 & $<0.001$ \\
\hline Odontoid retroversion & -0.260 & 0.055 & 0.039 & - & - \\
\hline $\mathrm{pB}-\mathrm{C} 2$ line & 0.794 & 0.071 & 0.019 & - & - \\
\hline
\end{tabular}

- = variable was not used in the multivariate model

* Multivariate model: $F(3,74)=8.581, R^{2}=0.258, p<0.001$.

Tubbs et al. previously showed that patients with Grade III odontoid angulation had a greater length of tonsillar ectopia than did patients with Grade II angulation..$^{20} \mathrm{We}$ found that increasing tonsillar ectopia was associated with increasing grade $(\mathrm{p}=0.015)$ and that increasing tonsillar ectopia generally was associated with increasing retroflexion ( $p<0.001, R^{2}=0.133$ ). Tubbs et al. showed no relationship between basiocciput length and angulation grade, which was confirmed in our population.

Understanding the role of odontoid angulation in CM-I-associated syringomyelia remains a challenge. Inferior obex displacement has been previously observed in Chiari malformation Types 0,1 , and $1.5 .^{15,18-20}$ Tubbs et al. hypothesized that posterior odontoid inclination in CM-I posteriorly tilts the brainstem at the obex, encouraging CSF egress into the central canal, and thus syringomyelia. ${ }^{20}$ They showed a significant relationship between odontoid angulation and syringomyelia, which is contrary to our findings. Moore and Moore also found that complicated CM-I cases, which had a greater obex displacement, were more likely to have a syrinx, although more rigorous assessment of this relationship was not conducted.13

Tubbs et al. additionally found that the obex-McRae line length correlated with degree of odontoid inclination, and that this measurement was shorter in patients with CM-I relative to controls. ${ }^{20}$ Overall, $60 \%$ of CM-I patients had an obex less than $2 \mathrm{~mm}$ above the foramen magnum; in contrast, $100 \%$ of controls had an obex more than 2.5 $\mathrm{mm}$ above the foramen magnum. However, the obex displacement in our population did not confirm the findings by Tubbs et al. To our surprise, this measurement in the Vanderbilt University population $(13.9 \mathrm{~mm})$ was more similar to the Tubbs et al. control population $(10 \mathrm{~mm})$ than the Tubbs et al. CM-I population $(2.1 \mathrm{~mm}) ; 100 \%$ of our patients had an obex greater than or equal to $4 \mathrm{~mm}$ above the foramen magnum. Only 3 patients $(3.8 \%)$ had an obex displaced less than or equal to $4 \mathrm{~mm}$.

In our series, obex displacement was measured from the most caudal portion of the fourth ventricle to the midpoint of McRae's line, in an attempt to be consistent with the description by Tubbs et al. There is some radiological subjectivity as to where the fourth ventricle ends, as it is of course continuous with the central canal. The fourth ven- tricle/central canal junction appears differently on MRI from that depicted by Tubbs et al., which may account for the difference in measurement between groups. However, the manner in which this measurement was made was standard across all patients in our cohort. We hypothesize also that this may reflect differences in referral trends and patient selection for complicated cases, which evolved over time. Indeed, Moore and Moore have recently shown that the obex is displaced more inferiorly below the foramen magnum in complex CM-I cases compared with uncomplicated cases $(-7.1 \mathrm{~mm}$ vs $4.3 \mathrm{~mm}) .^{13}$

We did not observe a statistically significant relationship between odontoid angulation versus obex displacement, obex displacement versus syringomyelia, or odontoid angulation versus syringomyelia. There was no evidence that progressive inclination of the odontoid resulted in any further tilting or displacement of the brainstem. While brainstem inclination may be a contributor to syringomyelia in select patients, we did not find evidence of this in our population.

A total of 54 patients $(69.2 \%)$ in this series presented with syrinx, which is higher than the figure reported by Tubbs et al. (52\%). ${ }^{20}$ As both of these series are from surgical populations, it is possible that referral bias and surgical candidate selection influenced these numbers. There was no difference in syrinx size, prevalence, or location in relationship to odontoid angulation. Inferior displacement of the brainstem at the level of the obex may be a risk factor, although this was not present in our study. While we did not show a relationship between odontoid angulation and syringomyelia like Tubbs et al., ${ }^{20}$ we did observe separately that a $\mathrm{pB}-\mathrm{C} 2$ line length greater than or equal to $3 \mathrm{~mm}$ (Grade I pB-C2 line) is associated with a greater incidence of syrinx, suggesting that some form of ventral canal encroachment predisposes to syringomyelia." ${ }^{11}$ That odontoid angulation did not correlate with syringomyelia whereas $\mathrm{pB}-\mathrm{C} 2$ line did might be explained by the length of the odontoid process. Length may be an effect modifier for the relationship between angulation and $\mathrm{pB}-\mathrm{C} 2$ line, as by trigonometry, a long, angulated process might project more into the ventral canal than a shorter, less angulated one. However, even when correcting for length in a logistic regression of odontoid angulation versus syrinx, there 
was still no relationship $(\mathrm{p}>0.05)$. These findings must be tested in a larger, external population.

\section{Basiocciput Hypoplasia in CM-I}

The presence of a normal-sized hindbrain in a small or shallow posterior cranial fossa is hypothesized to correlate with CM-I. However, there have been contradictory reports of the relative size of the posterior fossa volume in both adult and pediatric CM-I patients..$^{4,5,7,16-18}$ Noudel et al. found that the basiocciput is shorter in adults with CM-I. ${ }^{14}$ They proposed that early hypoplasia of the skull base osseous elements or the development of sphenooccipital craniosynostosis contribute to the posterior skull base shortening in CM-I. However, Tubbs et al. found no difference in children in the size of the basiocciput between patients $(23 \mathrm{~mm})$ and controls $(23 \mathrm{~mm}){ }^{20}$ We confirmed this finding in our population as well $(22 \mathrm{~mm})$. This was strengthened by our additional measurement of clivus length (37.8 $\mathrm{mm}$ ), which was consistent with a report by Furtado et al. that showed no significant difference between patients ( 35 $\mathrm{mm}$ ) and controls $(38 \mathrm{~mm}) .{ }^{6}$ Despite this, however, those authors did find a reduced posterior fossa volume in patients with CM-I. Our study is limited in that only a single dimension of the posterior fossa was analyzed, which may not be a reliable proxy for posterior fossa size.

\section{CCJ Measurement Differences Across Ages}

It appears that the odontoid height and $\mathrm{pB}-\mathrm{C} 2$ line length are increased, and that the odontoid process is also more posteriorly inclined, in older children. This is consistent with the literature in healthy adults, who have a longer and more posteriorly inclined odontoid process. Khaleel et al. found that the mean $\mathrm{pB}-\mathrm{C} 2$ line in adults was $6.5 \mathrm{~mm}$ versus $2.9 \mathrm{~mm}$ in children. ${ }^{9}$ These observations suggest that the odontoid process might become more angulated with age, although longitudinal imaging studies are warranted. With regard to odontoid height, Cokluk et al. found that the odontoid process was longer in adults than in children, which is consistent with our finding that odontoid height was longer in the older patients. ${ }^{3}$

\section{CCJ Measurements Differences Between Sexes}

There were more female patients included in this study than male $(55.1 \%$ vs $44.9 \%)$. The $\mathrm{pB}-\mathrm{C} 2$ line was significantly longer in girls, with a greater degree of retroversion. Unlike the Tubbs et al. cohort, in our cohort there was no apparent sex difference in odontoid retroflexion..$^{20} \mathrm{In}$ healthy adults, there do not appear to be sex differences in $\mathrm{pB}-\mathrm{C} 2$ line length. ${ }^{9}$ However, women tend to have a shorter and more posteriorly angulated odontoid process. Other reports have confirmed greater odontoid retroversion in female patients. ${ }^{10}$ To our knowledge, there are currently no reported studies of these particular measurements in adult CM-I patients, which would be helpful in evaluating whether the morphometric sex differences in these children persist into adulthood.

\section{CCJ Measurements Correlations With Symptomatology}

A total of 55 patients (70.5\%) in this series were symptomatic upon presentation. There were no differences in CCJ measurements between symptomatic and asymptomatic patients. When patients were stratified by odontoid angulation, we found differences in neither preoperative symptoms nor postoperative symptom resolution. However, we have separately found that $\mathrm{pB}-\mathrm{C} 2$ line length correlates with syrinx prevalence and resolution, as well as headache improvement. ${ }^{11}$ Asymptomatic patients more frequently presented with syringes, especially in the cervical spine. Given that this is a retrospective surgical series, the surgical referral and candidacy bias for patients with syrinx may affect the prevalence and size of syrinx in this population.

\section{Modeling Tonsillar Ectopia}

Odontoid angulation appeared to be closely linked to the extent of tonsillar descent. Each of the 3 markers of posterior odontoid inclination (retroflexion, retroversion, and $\mathrm{pB}-\mathrm{C} 2$ line) were all significantly associated with hindbrain herniation on univariate analysis. Tubbs et al. previously reported a trend toward increased ectopia with increasing grade, which was more pronounced in our population. ${ }^{20}$ These findings, along with the observation by Tubbs et al. that healthy controls have less posterior inclination of the odontoid process,${ }^{20}$ further support the role of a posteriorly angulated odontoid process in CM-I.

Three CCJ measurements (odontoid retroflexion, the McRae line, and obex displacement) independently correlated with the degree of tonsillar ectopia $\left(\mathrm{R}^{2}=0.258\right)$. We hypothesize that increasing angulation of the odontoid process into the ventral canal could create turbulent CSF flow as a result of a pressure gradient force at the CCJ. This force may cause increased descent of the hindbrain into the foramen magnum. In our model, every additional decrease of retroflexion by $4^{\circ}$ was associated with $1.5 \mathrm{~mm}$ of additional tonsillar ectopia.

An enlarged foramen magnum has been shown in patients with CM-I, which may allow for an increased volume of hindbrain herniation into the spinal canal. ${ }^{1,5}$ However, this is at odds with the finding that the McRae line is longer in healthy controls versus CM-I patients. ${ }^{9}$ This might be explained by a smaller posterior fossa in certain cases of CM-I, which becomes overcrowded and allows brain matter to slide into the foramen magnum; those CM-I patients with an enlarged foramen magnum might be expected to have a greater degree of herniation into the spinal canal as a result. Every $4 \mathrm{~mm}$ of foramen magnum enlargement was associated with $1 \mathrm{~mm}$ of additional tonsillar ectopia.

Finally, an inferiorly displaced obex is associated with tonsillar ectopia in CM-I. Whether this is a cause or consequence is debatable. It seems reasonable to conclude that exaggerated cerebellar tonsillar herniation would involve descent of hindbrain elements proximal to the tonsils. One could alternatively envision that additional volume of hindbrain herniated into the canal would add to the compression of the CCJ and increase the pressure gradient force, cooperatively increasing the degree of tonsillar ectopia. In our model, every $4 \mathrm{~mm}$ of obex displacement caudally was associated with $1 \mathrm{~mm}$ of additional tonsillar ectopia.

\section{Limitations}

This was a retrospective study, and the bias and data deficiencies inherent to any retrospective study must be considered. Only patients who underwent decompression 
were evaluated, introducing surgical candidate selection bias. There were no controls. The imaging in this study was reviewed by only a single neuroradiologist; a stronger study would have included another independent reviewer along with a calculated interrater reliability. Measurement of posterior fossa size only used 2 linear measurements in the same dimension, which would have been strengthened by additional assessment of posterior fossa volume. Finally, these findings only demonstrate an association, and not necessarily causation.

\section{Conclusions}

Anomalous bony development of the CCJ is a consistent feature of CM-I in children. We found that the population at our center was characterized by posterior angulation of the odontoid process in $81 \%$ of cases, similar to findings of Tubbs et al. (84\%). ${ }^{20}$ In pediatric CM-I, the odontoid process appeared to lengthen and become more posteriorly inclined with age. Increased tonsillar ectopia was associated with more posterior odontoid angulation, a widened foramen magnum, and an inferiorly displaced obex. As this study was only able to assess association, further studies are warranted to determine the causal relationship between these anomalies and the hindbrain herniation in CM-I.

\section{References}

1. Aboulezz AO, Sartor K, Geyer CA, Gado MH: Position of cerebellar tonsils in the normal population and in patients with Chiari malformation: a quantitative approach with MR imaging. J Comput Assist Tomogr 9:1033-1036, 1985

2. Bollo RJ, Riva-Cambrin J, Brockmeyer MM, Brockmeyer DL: Complex Chiari malformations in children: an analysis of preoperative risk factors for occipitocervical fusion. $\mathbf{J}$ Neurosurg Pediatr 10:134-141, 2012

3. Cokluk C, Aydin K, Rakunt C, Iyigun O, Onder A: The borders of the odontoid process of $\mathrm{C} 2$ in adults and in children including the estimation of odontoid/body ratio. Eur Spine J 15:278-282, 2006

4. Dagtekin A, Avci E, Kara E, Uzmansel D, Dagtekin O, Koseoglu A, et al: Posterior cranial fossa morphometry in symptomatic adult Chiari I malformation patients: comparative clinical and anatomical study. Clin Neurol Neurosurg 113:399-403, 2011

5. Dufton JA, Habeeb SY, Heran MK, Mikulis DJ, Islam O: Posterior fossa measurements in patients with and without Chiari I malformation. Can J Neurol Sci 38:452-455, 2011

6. Furtado SV, Reddy K, Hegde AS: Posterior fossa morphometry in symptomatic pediatric and adult Chiari I malformation. J Clin Neurosci 16:1449-1454, 2009

7. Furtado SV, Thakar S, Hegde AS: Correlation of functional outcome and natural history with clinicoradiological factors in surgically managed pediatric Chiari I malformation. Neurosurgery 68:319-328, 2011

8. Grabb PA, Mapstone TB, Oakes WJ: Ventral brain stem compression in pediatric and young adult patients with Chiari I malformations. Neurosurgery 44:520-528, 1999

9. Khaleel ZL, Besachio DA, Bisson EF, Shah LM: Estimation of odontoid process posterior inclination, odontoid height, and pB-C2 line in the adult population. J Neurosurg Spine 20:172-177, 2014

10. Koller H, Acosta F, Tauber M, Komarek E, Fox M, Moursy M, et al: C2-fractures: part I. Quantitative morphology of the $\mathrm{C} 2$ vertebra is a prerequisite for the radiographic assessment of posttraumatic $\mathrm{C} 2$-alignment and the investigation of clinical outcomes. Eur Spine J 18:978-991, 2009

11. Ladner TR, Dewan MC, Day MA, Shannon CN, Tomycz L, Tulipan N, et al: Evaluating the relationship of the pB-C2 line to clinical outcomes in a 15 -year single-center cohort of pediatric Chiari I malformation. J Neurosurg Pediatr 15:178-188, 2015

12. Milhorat TH, Chou MW, Trinidad EM, Kula RW, Mandell M, Wolpert C, et al: Chiari I malformation redefined: clinical and radiographic findings for 364 symptomatic patients. Neurosurgery 44:1005-1017, 1999

13. Moore HE, Moore KR: Magnetic resonance imaging features of complex Chiari malformation variant of Chiari 1 malformation. Pediatr Radiol 44:1403-1411, 2014

14. Noudel R, Jovenin N, Eap C, Scherpereel B, Pierot L, Rousseaux P: Incidence of basioccipital hypoplasia in Chiari malformation type I: comparative morphometric study of the posterior cranial fossa. Clinical article. J Neurosurg 111:1046-1052, 2009

15. Quisling RG, Quisling SG, Mickle JP: Obex/nucleus gracilis position: its role as a marker for the cervicomedullary junction. Pediatr Neurosurg 19:143-150, 1993

16. Sgouros S, Kountouri M, Natarajan K: Posterior fossa volume in children with Chiari malformation Type I. J Neurosurg 105 (2 Suppl):101-106, 2006

17. Trigylidas T, Baronia B, Vassilyadi M, Ventureyra ECG: Posterior fossa dimension and volume estimates in pediatric patients with Chiari I malformations. Childs Nerv Syst 24:329-336, 2008

18. Tubbs RS, Elton S, Grabb P, Dockery SE, Bartolucci AA, Oakes WJ: Analysis of the posterior fossa in children with the Chiari 0 malformation. Neurosurgery 48:1050-1055, 2001

19. Tubbs RS, Iskandar BJ, Bartolucci AA, Oakes WJ: A critical analysis of the Chiari 1.5 malformation. J Neurosurg 101 (2 Suppl):179-183, 2004

20. Tubbs RS, Wellons JC III, Blount JP, Grabb PA, Oakes WJ: Inclination of the odontoid process in the pediatric Chiari I malformation. J Neurosurg 98 (1 Suppl):43-49, 2003

\section{Author Contributions}

Conception and design: Ladner, Dewan, Day, Tomycz, Wellons. Acquisition of data: Ladner, Dewan, Day. Analysis and interpretation of data: Ladner, Dewan, Day, Shannon, Tomycz, Wellons. Drafting the article: Ladner, Dewan, Day, Shannon, Wellons. Critically revising the article: Ladner, Dewan, Day, Shannon, Tomycz, Wellons. Reviewed submitted version of manuscript: all authors. Approved the final version of the manuscript on behalf of all authors: Ladner. Statistical analysis: Ladner, Shannon. Administrative/technical/material support: Shannon, Wellons. Study supervision: Shannon, Tomycz, Tulipan, Wellons.

\section{Supplemental Information}

\section{Previous Presentation}

A portion of the findings herein were previously presented at the 42nd Annual Meeting of the AANS/CNS Section on Pediatric Neurological Surgery on December 3, 2013, in Toronto, Ontario, Canada. A related publication regarding the $\mathrm{pB}-\mathrm{C} 2$ line and neurosurgical outcomes in the same patient cohort has been previously published in the Journal of Neurosurgery: Pediatrics; however, the scope and discussion are substantially different.

\section{Correspondence}

Travis R. Ladner, Department of Neurological Surgery, Vanderbilt University School of Medicine, 2200 Children's Way, 9222 Doctors' Office Tower, Nashville, TN 37232. email: travis.r.ladner@vanderbilt.edu. 